\title{
Long-term Psychological and Occupational Effects of Providing Hospital Healthcare during SARS Outbreak
}

\author{
Robert G. Maunder, ${ }^{*} \dagger$ William J. Lancee, ${ }^{*} \dagger$ Kenneth E. Balderson, ${ }^{\star} \ddagger$ Jocelyn P. Bennett, ${ }^{*}$ \\ Bjug Borgundvaag, ${ }^{*} \dagger$ Susan Evans,§ Christopher M.B. Fernandes, $\Uparrow \#$ David S. Goldbloom, $\dagger^{* *}$ \\ Mona Gupta, $\uparrow \dagger \dagger$ Jonathan J. Hunter, ${ }^{*} \dagger$ Linda McGillis Hall, $\dagger$ Lynn M. Nagle, $\dagger$ Clare Pain, ${ }^{*} \dagger$ \\ Sonia S. Peczeniuk, $\ddagger$ Glenna Raymond,§§ Nancy Read,‡ Sean B. Rourke,†‡ Rosalie J. Steinberg, ${ }^{*} \dagger$ \\ Thomas E. Stewart, ${ }^{\star} \dagger$ Susan VanDeVelde-Coke, $\dagger \dagger$ Georgina G. Veldhorst,,$\uparrow \Uparrow$ \\ and Donald A. Wasylenki†‡
}

Healthcare workers (HCWs) found the 2003 outbreak of severe acute respiratory syndrome (SARS) to be stressful, but the long-term impact is not known. From 13 to 26 months after the SARS outbreak, $769 \mathrm{HCWs}$ at 9 Toronto hospitals that treated SARS patients and 4 Hamilton hospitals that did not treat SARS patients completed a survey of several adverse outcomes. Toronto HCWs reported significantly higher levels of burnout ( $p=0.019)$, psychological distress $(p<0.001)$, and posttraumatic stress $(p<0.001)$. Toronto workers were more likely to have reduced patient contact and work hours and to report behavioral consequences of stress. Variance in adverse outcomes was explained by a protective effect of the perceived adequacy of training and support and by a provocative effect of maladaptive coping style and other individual factors. The results reinforce the value of effective staff support and training in preparation for future outbreaks.

Cevere acute respiratory syndrome (SARS) emerged $\checkmark$ from Guangdong Province, People's Republic of China, in November 2002 and spread rapidly; transmission

*Mount Sinai Hospital, Toronto, Ontario, Canada; †University of Toronto, Toronto, Ontario, Canada; ‡Saint Michael's Hospital, Toronto, Ontario, Canada; §The Scarborough Hospital, Toronto, Ontario, Canada; ॠHamilton Health Sciences Centre, Hamilton, Ontario, Canada; \#McMaster University, Hamilton, Ontario, Canada; ${ }^{* *}$ Centre for Addiction and Mental Health, Toronto, Ontario, Canada; ††Sunnybrook and Women's Health Sciences Centre, Toronto, Ontario, Canada; ł‡Rouge Valley Health System, Toronto, Ontario, Canada; §§Whitby Mental Health Centre, Whitby, Canada; and ๆףNorth York General Hospital, Toronto, Ontario, Canada occurred primarily in hospitals, often to healthcare workers (HCWs). Although initially virtually no literature was available to guide expectations of how an emerging infection would affect the psychological well-being of hospital staff (1), by the summer of 2003 the acute psychological impact of SARS had been widely studied. Significant emotional distress was present in $18 \%-57 \%$ of HCWs (2-6) and was associated with quarantine (7), fear of contagion $(6,8,9)$, concern for family $(5,9,10)$, job stress $(6,9)$, interpersonal isolation $(6,9)$, perceived stigma $(6,7,11)$, conscription of nonspecialists into infectious disease work (12), and attachment insecurity (10).

Working in SARS-affected hospitals could have been traumatic for some HCWs (i.e., an event that "threatens an individual's life or physical integrity and involves a subjective response of fear, helplessness, or horror" [13]). Before the SARS coronavirus was identified (14-17), SARS was an infection of unknown cause, unknown mode of transmission, global spread, and high mortality, characteristics that generally increase perceived risk (18). However, although the SARS outbreak was acutely stressful, the longer term impact of SARS on HCWs is unknown.

Understanding the enduring occupational and psychological effects of working during this SARS outbreak is important because it involves the well-being of large numbers of HCWs. Additionally, this information has wider relevance to health systems in planning for emerging infections, including pandemic influenza (http://www. who.int/csr/disease/influenza/inforesources/en) and the potential for bioterrorism (19). Although healthcare work 
during the SARS outbreak and during an influenza pandemic will differ in key respects, SARS experience provides the most extensive information available about the effects on HCWs of a large-scale infectious outbreak. The objective of the Impact of SARS Study was to assess the long-term psychological and occupational impact of SARS outbreak on HCWs and to identify personal and systemic factors that increase vulnerability.

\section{Methods}

\section{Design, Setting, and Participants}

The study took place in hospitals in Toronto and Hamilton in Ontario, Canada. Most of Canada's 438 suspected and probable SARS cases were identified in Toronto. Hamilton HCWs were selected as a comparison group because Hamilton is $57 \mathrm{~km}$ from Toronto and experienced all of the healthcare processes and precautions associated with Ontario's response to SARS (e.g., restrictions on access to care, protocols for staff screening, isolation procedures) but did not have SARS patients. Hamilton and Toronto hospitals are otherwise similar in terms of size, workload, and organizational characteristics. Thirteen participating sites (9 Toronto, 4 Hamilton) included academic and community hospitals. All Toronto sites treated SARS patients. Eligible HCWs included nurses in medical and surgical inpatient units and all staff of intensive care units, emergency departments, and SARS isolation units. Fifty-five clinical units participated (Toronto 40, Hamilton 15) from October 23, 2004, to September 30, 2005. This study was approved by the Research Ethics Board of each hospital.

Survey A measured adverse outcomes. All participants completed survey A anonymously and received Can \$10. Those who were willing to provide more information participated in survey $\mathrm{B}$, which measured potential mediators of adverse outcomes, and in 2 structured interviews (results to be reported elsewhere). Participants in survey B also received $\$ 50$.

A separate "representativeness survey" was conducted from September through November 2005 to compare eligible Toronto HCWs who had participated in the Impact of SARS Study with those who had not. HCWs were approached at staff meetings in 14 participating clinical units and asked to complete an anonymous, 6-question questionnaire that surveyed whether or not they had participated in the Impact of SARS Study, exposure to SARS patients, age range, job type, years of healthcare experience, and overall subjective impact of SARS on their lives.

\section{Measures}

In the study instruments, "during the SARS outbreak" was defined for Toronto HCWs as the period from
February 2003 to the day the last SARS patient was discharged from a participant's hospital or died. For Hamilton HCWs, the comparable period was defined as February through September 2003. SARS patients included probable and suspected SARS patients and persons isolated while their cases were under investigation for SARS according to the participants' report, rather than by using case definitions (http://www.phac-aspc.gc.ca/sarssras/sarscasedef_e.html).

\section{Survey A}

This survey measured demographic and job data as well as traumatic stress response (15-item Impact of Events Scale [IES] $[20,21])$, nonspecific psychological distress (Kessler Psychological Distress Scale [K10] [22]), and professional burnout (emotional exhaustion scale of the Maslach Burnout Inventory [MBI-EE] [23-25]). To measure the practical and functional impact of SARS experience, participants were surveyed about changes since the SARS outbreak in healthcare work hours and the amount of face-to-face contact with patients in their work. Survey A also asked if survey participants had experienced an increase since the SARS outbreak in smoking, drinking alcohol, or "other activities that could interfere with your work or relationships" and how many work shifts had been missed in the 4 months preceding the survey because of stress, illness, or fatigue.

\section{Survey B}

Survey B, by using a previously described instrument, measured SARS-related perception of stigma and interpersonal avoidance; adequacy of training, protection, and support; and job stress $(6,10,26)$. Scales calculated as the mean of all items related to these constructs showed adequate internal reliability (Table 1). Adaptive coping (problem-solving, seeking support, positive reappraisal) and maladaptive coping (escape-avoidance, self-blame, confrontative coping) regarding SARS were measured with the relevant subscales of the Ways of Coping Questionnaire (27), for which the stressful event was defined as the SARS outbreak. Attachment insecurity was measured with the anxiety and attachment avoidance scales of the Experiences in Close Relationships-Revised questionnaire (28).

\section{Statistical Analysis}

Central tendencies of parametric variables are described by mean and standard deviation; nonparametric variables are described by median and interquartile range. Between-group differences in parametric variables were determined by Student $t$ test and in nonparametric variables by Mann-Whitney $U$ test. To make the identified between-city differences more clinically meaningful, the 
Table 1. Scales to measure perceptions about severe acute respiratory syndrome (SARS) experience

\begin{tabular}{|c|c|}
\hline Scale & Perception \\
\hline $\begin{array}{l}\text { Training, protection and } \\
\text { support }^{*} \\
\text { Cronbach } \alpha=0.89\end{array}$ & $\begin{array}{l}\text { I had adequate training to deal confidently with the situations that I faced. } \\
\text { Infection control procedures were adequately explained. } \\
\text { I received adequate training in infection control procedures. } \\
\text { I was provided with the protective equipment and procedures that I needed. } \\
\text { I had someone to ask when I had problems using equipment. } \\
\text { The hospital where I worked took my well-being into account when decisions were made that affected me. } \\
\text { Emotional support (e.g., counseling) was available to those who needed help. } \\
\text { I felt appreciated by the hospital/clinic/my employer. } \\
\text { My hospital/workplace was supportive. }\end{array}$ \\
\hline $\begin{array}{l}\text { Job stress } \dagger \\
\text { Cronbach } \alpha=0.76\end{array}$ & $\begin{array}{l}\text { There was more conflict among colleagues at work. } \\
\text { I felt more stressed at work. } \\
\text { I had to do work that normally I don't do. } \\
\text { I had an increase workload. } \\
\text { I had to work overtime. }\end{array}$ \\
\hline $\begin{array}{l}\text { Perceived stigma and } \\
\text { interpersonal avoidance } \\
\text { Cronbach } \alpha=0.77\end{array}$ & $\begin{array}{l}\text { I thought that people avoided me because of my profession. } \\
\text { I thought that people avoided my family members because of my profession. } \\
\text { I coped with the SARS situation by avoiding crowded places. } \\
\text { I coped with the SARS situation by avoiding colleagues who might be exposed. }\end{array}$ \\
\hline
\end{tabular}

*Items scored on a 5-point scale from 1 (very confident that this is false) to 5 (very confident that this is true).

tltems scored on a 6-point scale from 1 (strongly disagree) to 6 (strongly agree).

prevalence of high scores was determined with standard cutoff values: IES $\geq 26$ (http://www.mardihorowitz.com), MBI-EE $\geq 27$ (25), K10 $\geq 16$ (http://www.crufad.unsw. edu.au). Between-group differences in categorical variables were tested by $\chi^{2}$.

To identify factors that might explain variance in adverse outcome, between-group differences in traumatic stress symptoms, psychological distress, and burnout were tested for the following categories: gender; duration of healthcare experience; job type; regular work during the SARS outbreak in emergency department, intensive care unit, or SARS isolation unit; indicators of the frequency and intensity of contact with SARS patients; and exposure to quarantine. A 10-day cutoff for quarantine was used, which corresponds to the standard period of quarantine for SARS (i.e., quarantine $>10$ days indicates extended quarantine or $>1$ period of quarantine). This analysis was performed in the full sample.

The relationship between adverse outcomes and potential mediating factors was identified by using Spearman rank-order correlations between adverse outcomes and measures of perceived systemic characteristics (stigma and interpersonal avoidance, adequacy of training, protection and support, and job stress) and psychological variables (coping style and attachment insecurity). This analysis was performed for survey A and B participants.

A stepwise regression analysis was performed for each adverse outcome. All potential mediating factors (those identified in the preceding univariate analyses with a significance of $\mathrm{p}<0.05$ ) were entered. This analysis was performed for survey A and B participants.

Finally, to determine if factors that increase personal perceptions of risk had a practical functional impact on
HCWs in the full sample, we identified an item in survey A that could serve as a proxy for the survey B factors that mediate vulnerability. This item is the duration (in months) of continuing perceived increased risk after the last SARS patient was discharged from a study participant's hospital or died. Duration of perceived risk was significantly correlated with the 2 SARS-specific mediating factors identified in the regression analysis: 1) maladaptive coping and perceived adequacy of training and 2) protection and support. For this analysis, the functional impact of SARS experience was operationalized as the number of adverse outcomes experienced by a person (from 0 to 7 ) of the following 7 outcomes: posttraumatic stress (IES $\geq 26$ ); psychological distress $(\mathrm{K} 10 \geq 16)$; burnout (MBI-EE $\geq 27$ ); decrease in face-to-face patient contact since SARS; decrease in work hours since SARS; increase in smoking, alcohol, or other problematic behavior since SARS; and $\geq 4$ shifts missed because of stress or illness in the 4 months before the survey.

\section{Results}

In total, 1,984 HCWs received detailed information about the Impact of SARS Study and 769 (39\%) completed survey A. The interval between the last SARS patient discharged or deceased and study participation was 13-25 (median 19) months.

To determine how representative participants were of all eligible hospital staff, after the Impact of SARS Study a representativeness study was presented to 258 Toronto HCWs who had been eligible; it was completed by 255 (99\%) of these HCWs. Exposure to SARS patients was more common in HCWs who participated in the Impact of SARS Study than those who did not. However, study par- 
ticipants and nonparticipants did not differ in age range, job type, years of healthcare experience, or overall subjective impact of SARS on their lives (Table 2).

Of the 769 participants, $73.5 \%$ were nurses $(69.4 \%$ staff nurse, 3.1\% manager or educator, 1.0\% infection control practitioner). The next most prevalent job types were clerical staff (8.3\%), physicians $(2.9 \%)$, and respiratory therapists (2.3\%). The remaining 99 participants (12.9\%) were distributed among 14 different job types. Other characteristics of study participants, by city of employment, are presented in Table 3. Most Toronto participants (71.6\%) reported contact with SARS patients, and Toronto participants were much more likely than Hamilton participants to have experienced quarantine ( $47.9 \%$ vs. $1.6 \%$, $\mathrm{p}<0.001$ ), which confirms the anticipated difference in SARS-related experience between comparison groups. A higher proportion of Hamilton participants were nurses (Hamilton $84.1 \%$ nurses vs. Toronto $71.2 \%, \mathrm{p}=0.001$ ).

Survey B was completed by 187 HCWs (survey A and B participants). Survey A and B participants did not differ significantly from participants who only completed survey A by sex, job type (nurse or other), or city of employment. Survey A and B participants were older (mean $45 \pm$ standard deviation 9 years vs. $41 \pm 10$ years, $\mathrm{p}<0.001$ ) and more experienced in healthcare work ( $21 \pm 10$ years versus $16 \pm 10$ years, $\mathrm{p}<0.001)$. Survey A-only participants and Survey A and B participants did not differ with respect to exposure to SARS patients, working $\geq 5$ shifts in intensive care unit, emergency department or SARS isolation unit during the outbreak or with respect to traumatic stress symptoms, psychological distress, or burnout.

During the study period (13-25 months after the SARS outbreak), Toronto HCWs reported significantly higher levels of burnout (Toronto median score 19, interquartile range 10-29; Hamilton 16, 9- 23, $\mathrm{p}=0.019$ ), psychologi- cal distress (Toronto 15, 12-19; Hamilton 13, 11-17, $\mathrm{p}<0.001$ ), and posttraumatic stress (Toronto 11, 4-21; Hamilton 7, 0-19, p<0.001). To make these differences more clinically meaningful, the prevalence of high scores was calculated (Table 4). The prevalence of the following functional indicators of distress since the SARS outbreak was higher in Toronto HCWs: decrease in patient contact and work hours, increase in substance use and other traits that interfere with function, and more days off work (Table 4). Of the 7 adverse outcomes reported in Table 4, Toronto HCWs were more likely to be experiencing $\geq 1$ problem (Toronto $68.1 \%$ vs. Hamilton $50.1 \%, \mathrm{p}<0.001$ )) and were almost twice as likely to be experiencing multiple $(\geq 2)$ problems (Toronto 44.0\% vs. Hamilton 22.5\%, $\mathrm{p}<0.001$ ).

Personal and occupational characteristics of participants and the relationship of these variables to adverse outcomes are shown in Tables 5 and 6. Univariate relationships significant at the level of $\mathrm{p}<0.05$ were retained for stepwise regression analysis to determine which of these variables accounted for significant variance in each adverse outcome (Table 7). Maladaptive coping and perceived adequacy of training together with protection and support explained $18 \%$ of the variance in burnout. The same 2 variables explained 21\% of the variance in posttraumatic stress. Maladaptive coping and attachment anxiety, together with a protective effect of experience in healthcare, explained $31 \%$ of the variance in psychological distress.

Finally, the functional impact of vulnerability factors on the full survey A sample was tested by using duration of perceived risk after SARS as a proxy for the SARS-related vulnerability factors identified in the regression analysis. Duration of post-SARS perceived risk was correlated with maladaptive coping (Spearman $\rho=0.28, \mathrm{p}=0.001$ ) and perceived adequacy of training, protection, and sup-

\begin{tabular}{|c|c|c|c|}
\hline \multirow[b]{2}{*}{ Characteristics } & \multicolumn{2}{|c|}{ Participation in Impact of SARS Study } & \multirow[b]{2}{*}{$p$ value } \\
\hline & Did not participate, $\%(n=144)$ & Participated, \% $(n=111)$ & \\
\hline \multicolumn{4}{|l|}{ Age group, y } \\
\hline$<40$ & 53 & 44 & \\
\hline$\geq 40$ & 47 & 56 & 0.17 \\
\hline \multicolumn{4}{|l|}{ Job type } \\
\hline Nurse & 73 & 71 & \\
\hline Other & 27 & 29 & 0.76 \\
\hline \multicolumn{4}{|l|}{ Experience, y } \\
\hline$<10$ & 51 & 41 & \\
\hline$\geq 10$ & 49 & 59 & 0.12 \\
\hline \multicolumn{4}{|c|}{ Treated SARS patient } \\
\hline Yes & 31 & 59 & \\
\hline No or don't know & 69 & 41 & $<0.001$ \\
\hline \multicolumn{4}{|l|}{ Overall impact } \\
\hline Bad & 40 & 50 & \\
\hline Neutral or good & 60 & 50 & 0.11 \\
\hline
\end{tabular}


Table 3. Demographic and job characteristics of participants, Impact of SARS Study

\begin{tabular}{|c|c|c|c|}
\hline Characteristics & Toronto $\%(n=587)$ & Hamilton \% $(n=182)$ & $p$ value \\
\hline Female & 86.0 & 89.6 & 0.22 \\
\hline Single & 23.7 & 20.3 & \\
\hline Married or common-law & 65.2 & 68.1 & \\
\hline Separated or widowed & 11.1 & 11.5 & 0.41 \\
\hline Living with child $\leq 16$ y of age & 36.3 & 36.8 & 0.90 \\
\hline Living with adult $\geq 65$ y of age & 9.2 & 5.5 & 0.11 \\
\hline Worked in healthcare $\geq 10 \mathrm{y}$ & 65.1 & 68.7 & 0.37 \\
\hline \multicolumn{4}{|l|}{ Worked any shifts during SARS in } \\
\hline Surgical inpatient unit & 13.8 & 18.7 & 0.11 \\
\hline Medical inpatient unit & 26.4 & 21.4 & 0.18 \\
\hline Isolation unit with SARS patients & 22.5 & $\dagger$ & \\
\hline Intensive care unit & 32.9 & 34.1 & 0.66 \\
\hline Emergency department & 32.2 & 24.7 & 0.06 \\
\hline
\end{tabular}

*SARS, severe acute respiratory syndrome.

tHamilton had no patients with SARS.

port (Spearman $\rho=-0.27, p=0.001$ ). The Figure shows a linear increase in the prevalence of multiple adverse outcomes in HCWs with longer duration of perceived risk. Duration of perceived risk and the overall number of adverse outcomes were significantly correlated. (Spearman $\rho=0.23, p=0.005$ ).

\section{Discussion}

This study highlights the resiliency of HCWs and, despite this trait, the potential that working during the SARS outbreak had a substantial negative impact on a statistically significant number of people. The evaluation of mediating factors suggests both systemic and individual targets for interventions to buffer the adverse effects of an extraordinary outbreak of infectious disease. Systemically, enhanced support and training may reduce burnout and posttraumatic stress. Individually, interventions that reduce maladaptive coping may decrease prolonged suffering.

The differences in adverse outcomes between Toronto and Hamilton HCWs were significant but small. However, further analysis suggests that the long-term impact of SARS has not been trivial. In particular, a categorical analysis (Table 4) shows that long-term adverse outcomes in Toronto HCWs occurred at a prevalence $\approx 50 \%-100 \%$ higher than in Hamilton HCWs. Furthermore, these outcomes may have a systemic impact, since SARS-affected
HCWs reported reducing patient contact and hours of healthcare work as well as more frequent sick absences and an increase in behavior that could affect function.

These findings can be framed in terms of their potential value for the future. If the emergence of a new infectious disease is likely to increase the prevalence of significant distress in HCWs by $50 \%$, to double the number of HCWs who are reducing their clinical practice or calling in sick, and if these difficulties will persist for $\geq 1-2$ years after the outbreak's resolution, we want to learn from the SARS experience to try to buffer this negative impact. This discussion, therefore, addresses the identified mediators of SARS-related distress in HCWs and how these can guide preparation for pandemic influenza and other infectious disease outbreaks.

Exposure to high-intensity and high-risk work settings (such as intensive care units and emergency department work) and direct exposure to infected patients were not the primary determinants of adverse psychological outcomes. In fact, trends toward lower burnout in intensive care unit workers and less general psychological distress in emergency department workers were noted. These trends may be explained by the resilience of HCWs who choose this type of work and are consistent with the findings that longer healthcare experience was protective. We also found that the extent of various forms of distress was

\begin{tabular}{lccc}
\hline Table 4. Prevalence of adverse outcomes in Hamilton and Toronto healthcare workers* & & \\
\hline Adverse outcomes & Toronto, $\mathrm{n}=587, \%$ & Hamilton, $\mathrm{n}=182, \%$ & $\mathrm{p}$ value \\
\hline High burnout (MBI-EE score $\geq 27$ ) & 30.4 & 19.2 & 0.003 \\
High psychological distress (K10 score $\geq 16$ ) & 44.9 & 30.2 & $<0.001$ \\
High posttraumatic stress (IES score $\geq 26$ ) & 13.8 & 8.4 & 0.06 \\
Since SARS have & & 8.3 & 0.007 \\
$\quad$ Decreased face-to-face patient contact & 16.5 & 2.2 & 0.003 \\
$\quad$ Decreased work hours & 8.6 & 8.1 & 0.001 \\
Increased smoking, drinking alcohol, or other behavior & 21.0 & & 0.007 \\
$\quad$ that could interfere with work or relationships & & $12.6 \%$ & \\
$\quad$ Missed $\geq 4$ work shifts because of stress or illness & $21.6 \%$ & & \\
\hline
\end{tabular}

*MBI-EE, Maslach Burnout Inventory; K10, Kessler Psychological Distress Scale; IES, Impact of Events Scale; SARS, severe acute respiratory syndrome. 
increased in Toronto HCWs, irrespective of their degree of contact with SARS patients, which implies that factors that are associated with the hospital environment as a whole and healthcare work in general during the outbreak were provocative.
Both systemic and personal variables were associated with persisting distress. In contrast to studies of distress during and shortly after the SARS outbreak $(6,9,12)$, job stress related to conflict, workload, and conscription to new duties did not mediate long-term outcome. However,

Table 5. Relationship of healthcare worker, job, and SARS exposure characteristics to adverse outcomes in Toronto healthcare workers*

\begin{tabular}{|c|c|c|c|c|c|c|c|c|c|c|}
\hline \multirow[b]{2}{*}{ Characteristics } & \multirow[b]{2}{*}{$\mathrm{n}$} & \multicolumn{3}{|c|}{ Burnout } & \multicolumn{3}{|c|}{ Psychological distress } & \multicolumn{3}{|c|}{ Posttraumatic stress } \\
\hline & & Median & $\begin{array}{c}\text { Interquartile } \\
\text { range }\end{array}$ & $\begin{array}{c}p \\
\text { value }\end{array}$ & Median & $\begin{array}{c}\text { Interquartile } \\
\text { range }\end{array}$ & $\begin{array}{c}\mathrm{p} \\
\text { value }\end{array}$ & Median & $\begin{array}{c}\text { Interquartile } \\
\text { range }\end{array}$ & $\begin{array}{c}\mathrm{p} \\
\text { value }\end{array}$ \\
\hline \multicolumn{11}{|l|}{ Sex } \\
\hline Male & 82 & 18 & $9-29$ & & 14 & $12-19$ & & 10 & $2-19$ & \\
\hline Female & 505 & 19 & $10-29$ & 0.30 & 15 & $12-19$ & 0.91 & 12 & $4-21$ & 0.02 \\
\hline \multicolumn{11}{|l|}{ Job type } \\
\hline Nurse & 418 & 21 & $11-29$ & & 14 & $11-18$ & & 12 & $5-22$ & \\
\hline Other & 169 & 14 & $8-27$ & 0.002 & 15 & $12-20$ & 0.16 & 10 & $2-19$ & 0.1 \\
\hline \multicolumn{11}{|l|}{$\begin{array}{l}\text { Healthcare } \\
\text { experience }\end{array}$} \\
\hline$<10 y$ & 205 & 21 & $12-30$ & & 16 & $12-21$ & & 11 & $11-21$ & \\
\hline$\geq 10 y$ & 382 & 18 & $10-28$ & 0.82 & 14 & $11-18$ & 0.03 & 11 & $5-22$ & 0.06 \\
\hline \multicolumn{11}{|c|}{$\begin{array}{l}\text { Worked on SARS } \\
\text { unit }\end{array}$} \\
\hline$<5$ shifts & 498 & 19 & $10-30$ & & 15 & $12-19$ & & 12 & $4-22$ & \\
\hline$\geq 5$ shifts & 89 & 17 & $11-26$ & 0.75 & 15 & $11-20$ & 0.54 & 10 & $3-17$ & 0.63 \\
\hline \multicolumn{11}{|l|}{ Worked in ICU } \\
\hline$<5$ shifts & 427 & 20 & $10-30$ & & 15 & $12-19$ & & 11 & $4-21$ & \\
\hline$\geq 5$ shifts & 160 & 17 & $9-17$ & 0.02 & 14 & $11-20$ & 0.29 & 11 & $3-22$ & 0.46 \\
\hline \multicolumn{11}{|l|}{$\begin{array}{l}\text { Worked in } \\
\text { Emergency }\end{array}$} \\
\hline$<5$ shifts & 434 & 18 & $10-28$ & & 15 & $12-20$ & & 12 & $5-21$ & \\
\hline$\geq 5$ shifts & 153 & 21 & $10-32$ & 0.12 & 13 & $11-17$ & 0.005 & 9 & $2-21$ & 0.24 \\
\hline \multicolumn{11}{|l|}{$\begin{array}{l}\text { Ever in SARS } \\
\text { patient room }\end{array}$} \\
\hline No & 167 & 19 & $9-30$ & & 15 & $12-19$ & & 11 & $4-22$ & \\
\hline Yes & 420 & 19 & $10-28$ & 0.33 & 15 & $11-19$ & 0.09 & 12 & $4-21$ & 0.16 \\
\hline \multicolumn{11}{|l|}{$\begin{array}{l}\text { Touched SARS } \\
\text { patient }\end{array}$} \\
\hline No & 265 & 19 & $9-30$ & & 15 & $11-19$ & & 12 & $4-22$ & \\
\hline Yes & 322 & 19 & $11-28$ & 0.42 & 15 & $12-19$ & 0.32 & 11 & $4-22$ & 0.41 \\
\hline \multicolumn{11}{|c|}{$\begin{array}{l}\text { Protected contact } \\
\text { with saliva or } \\
\text { phlegm of SARS } \\
\text { patient }\end{array}$} \\
\hline No & 438 & 19 & $9-29$ & & 15 & $12-19$ & & 11 & $4-21$ & \\
\hline Yes & 149 & 19 & $11-29$ & 0.43 & 15 & $12-18$ & 0.78 & 10 & $4-22$ & 0.44 \\
\hline \multicolumn{11}{|c|}{$\begin{array}{l}\text { Unprotected } \\
\text { exposure to SARS } \\
\text { patient }\end{array}$} \\
\hline No & 502 & 18 & $9-28$ & & 15 & $11-19$ & & 11 & $4-21$ & \\
\hline Yes & 85 & 24 & $13-32$ & 0.012 & 16 & $13-22$ & 0.08 & 13 & $6-22$ & 0.38 \\
\hline \multicolumn{11}{|c|}{$\begin{array}{l}\text { In SARS patients' } \\
\text { rooms }>5 \text { min, }>5 \\
\text { times }\end{array}$} \\
\hline No & 316 & 18 & $9-28$ & & 15 & $11-18$ & & 11 & $3-21$ & \\
\hline Yes & 271 & 20 & $11-31$ & 0.08 & 15 & $12-21$ & 0.02 & 11 & $5-22$ & 0.24 \\
\hline \multicolumn{11}{|l|}{ Quarantined } \\
\hline Never & 252 & 19 & $9-28$ & & 15 & $11-19$ & & 11 & $4-22$ & \\
\hline$\leq 10 \mathrm{~d}$ & 235 & 17 & $10-28$ & & 15 & $11-19$ & & 11 & $3-21$ & \\
\hline$>10 \mathrm{~d}$ & 100 & 21 & $11-34$ & 0.36 & 16 & $12-22$ & 0.09 & 13 & $5-22$ & 0.42 \\
\hline
\end{tabular}

*SARS, severe acute respiratory syndrome. 
Table 6. Correlation between adverse outcomes after SARS and perceived characteristics of workplace and environment, coping style, and attachment insecurity in Toronto healthcare workers ${ }^{\star}$

\begin{tabular}{|c|c|c|c|c|c|c|}
\hline \multirow{2}{*}{$\begin{array}{l}\text { Characteristics of } \\
\text { healthcare workers }\end{array}$} & \multicolumn{2}{|c|}{ Burnout } & \multicolumn{2}{|c|}{ Psychological distress } & \multicolumn{2}{|c|}{ Posttraumatic stress } \\
\hline & Spearman $\rho$ & $p$ value & Spearman $\rho$ & $p$ value & Spearman $\rho$ & $p$ value \\
\hline $\begin{array}{l}\text { Training, protection } \\
\text { and support }\end{array}$ & -0.297 & $<0.001$ & -0.162 & 0.06 & -0.269 & 0.001 \\
\hline Stigma and avoidance & 0.153 & 0.07 & 0.080 & 0.36 & 0.302 & $<0.001$ \\
\hline Job stress & 0.312 & $<0.001$ & 0.224 & 0.008 & 0.164 & 0.052 \\
\hline Adaptive coping & 0.066 & 0.44 & 0.147 & 0.08 & 0.182 & 0.03 \\
\hline Maladaptive coping & 0.261 & 0.002 & 0.312 & $<0.001$ & 0.364 & $<0.001$ \\
\hline Attachment anxiety & 0.179 & 0.049 & 0.355 & $<0.001$ & 0.295 & 0.001 \\
\hline Attachment avoidance & 0.078 & 0.40 & 0.204 & 0.03 & 0.139 & 0.13 \\
\hline
\end{tabular}

*SARS, severe acute respiratory syndrome.

perceived adequacy of training, moral support, and protection were associated with better outcome. When the lessons of SARS are applied to pandemic planning, effective staff support may be a primary target to bolster the resilience of HCWs who will face future outbreaks. This observation is consistent with ones made during the SARS outbreak regarding the benefits of responsive communication (29), opportunities for facilitated reflection on normal emotional responses to extraordinary stress, and opportunities for HCWs to contribute to decision-making in the workplace $(10,30)$.

Effective support benefits from careful planning and preparation before an outbreak, which the SARS situation did not allow. For example, effective moral or psychological support typically occurs in the context of trusted professional and institutional relationships, which should ideally be established before the outbreak situation. In particular, burnout has been identified as 1 of the most substantial health-related problems facing nurses (31). Because future outbreaks are likely to increase job strain and burnout, the prepandemic period is a critical time to attend to organizational characteristics that are known to buffer burnout, which include reducing patient-to-nurse ratios (32) and increasing organizational characteristics that increase nurses' autonomy, flexibility, control over practice (33), and perceived empowerment (34). The results of our study suggest that supportive interventions may be especially important for HCWs with fewer years of experience, who were more likely to experience prolonged psychological distress. Opportunities for mentorship or "buddying” with more experienced colleagues may be useful (35).

The personal variables that contributed to adverse outcomes were maladaptive coping through avoidance, hostile confrontation, and self-blame, and in the instance of general psychological distress, attachment anxiety. Although a review of interventions to modify coping style is beyond the scope of this paper, we note that organizational approaches to support staff and the individual experience of workers coping with extraordinary events are related. Hospital-based interventions to support staff may also promote adaptive coping. For example, engaging staff in collaborative planning for future outbreaks may reduce the tendency to cope by means of avoidant strategies and may enhance coping through problem-solving and peersupport. Anger and blame directed toward others (hostile confrontation) or oneself (self-blame) may be reduced in a working environment that fosters positive working rela-

\begin{tabular}{|c|c|c|c|}
\hline Variables & $\beta$ & $t$ & $\mathrm{p}$ value \\
\hline \multicolumn{4}{|l|}{ Dependent variable: burnout* } \\
\hline Maladaptive coping & 0.29 & 3.34 & 0.001 \\
\hline $\begin{array}{l}\text { Perceived adequacy of training, protection and support } \\
\text { Model } R^{2}=0.18, p \text { value }<0.001\end{array}$ & -0.27 & -3.10 & 0.002 \\
\hline \multicolumn{4}{|l|}{ Dependent variable: psychological distress $†$} \\
\hline Maladaptive coping & 0.31 & 3.78 & $<0.001$ \\
\hline Years of healthcare experience & -0.26 & -3.28 & 0.001 \\
\hline $\begin{array}{l}\text { Attachment anxiety } \\
\text { Model } R^{2}=0.31, p \text { value }<0.001\end{array}$ & 0.24 & 2.87 & 0.005 \\
\hline \multicolumn{4}{|l|}{ Dependent variable: posttraumatic stress $\ddagger$} \\
\hline Maladaptive coping & 0.37 & 4.39 & $<0.001$ \\
\hline $\begin{array}{l}\text { Perceived adequacy of training, protection and support } \\
\text { Model } R^{2}=0.21, p \text { value }<0.001\end{array}$ & -0.22 & -2.63 & 0.01 \\
\hline
\end{tabular}

*Excluded variables: job stress, attachment anxiety, job type, worked in intensive care unit, unprotected contact with SARS patient(s). tExcluded variables: job stress, attachment avoidance, worked in emergency department, in SARS patients room $>5$ min or $>5$ times. \#Excluded variables: perceived stigma and avoidance, adaptive coping, attachment anxiety, job type, sex. 


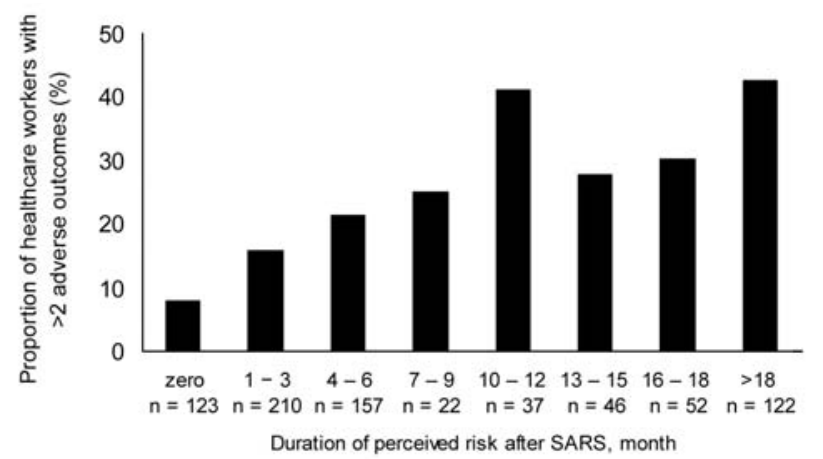

Figure. Relationship between prolonged perception of personal risk and reporting multiple adverse consequences of severe acute respiratory syndrome (SARS) in Toronto healthcare workers. Adverse outcomes are burnout; psychological distress; posttraumatic stress; decrease in face-to-face patient time since SARS; decrease in work hours since SARS; increase in smoking, drinking alcohol or other behavior that might interfere with work or relationships since SARS; and $\geq 4$ work shifts missed because of stress or illness in the past 4 months.

tionships through effective leadership (36). Attachment anxiety is a common, relatively enduring, and stable interpersonal style within close relationships (37), which is known to be associated with sensitivity to stress under many conditions $(38,39)$. Attachment anxiety is probably not a sensible target for hospital-based interventions to buffer the impact of systemic stresses, but it is a marker of those at greater risk for general psychological distress.

The results of this study also have implications for mitigating the effects of an infectious outbreak in the postoutbreak period. Because the duration of perceived risk in HCWs after the resolution of SARS is correlated with the severity of outcome, identifying and supporting HCWs who are at the highest risk for multiple and persistent psychological and occupational consequences of an outbreak may be possible by identifying HCWs whose perceived risk has not returned to normal within a few months after the event. Support programs, it would appear, need to be longer term to deal with ongoing residual effects after an outbreak. Programs directed toward healthy lifestyles, diet, exercise, and smoking cessation may also be important after the occurrence of an outbreak such as SARS to provide support to staff. Furthermore, for pandemic planning, the likelihood of prolonged subjective distress in a substantial percentage of HCWs should be factored into surge capacity modeling during and after the pandemic, particularly because distress is associated with reduced healthcare work.

Our conclusions are limited by the study method. With respect to generalizability, despite a response rate of 39\%, the representativeness survey suggests that HCWs who participated were similar to nonparticipants. HCWs who had contact with SARS patients are overrepresented in the study sample, which may be because the study had greater salience for those persons, but study participants and nonparticipants did not differ in the subjective impact attributed to the SARS experience. A further limitation is that self-reports of SARS experiences do not provide an objective evaluation of actual differences in the training, protection, or support that HCWs received. Regardless of the limitations, the Impact of SARS Study provides a window on the long-term effects of working during times of extraordinary infectious risk.

This study was funded with a research operating grant from the Canadian Institutes of Health Research.

Dr Maunder is a consultation-liaison psychiatrist whose research interest is in the interface between physical disease and psychological health. He was an author of the first published report of the psychological impact of SARS during the outbreak.

\section{References}

1. Maunder R, Hunter J, Vincent L, Bennett J, Peladeau N, Leszcz M, et al. The immediate psychological and occupational impact of the 2003 SARS outbreak in a teaching hospital. CMAJ. 2003;168:1245-51.

2. Tam CW, Pang EP, Lam LC, Chiu HF. Severe acute respiratory syndrome (SARS) in Hong Kong in 2003: stress and psychological impact among frontline healthcare workers. Psychol Med. 2004;34:1197-204.

3. Chan AO, Huak CY. Psychological impact of the 2003 severe acute respiratory syndrome outbreak on health care workers in a medium size regional general hospital in Singapore. Occup Med (Lond). 2004;54:190-6.

4. Phua DH, Tang HK, Tham KY. Coping responses of emergency physicians and nurses to the 2003 severe acute respiratory syndrome outbreak. Acad Emerg Med. 2005;12:322-8.

5. Nickell LA, Crighton EJ, Tracy CS, Al Enazy H, Bolaji Y, Hanjrah S, et al. Psychosocial effects of SARS on hospital staff: survey of a large tertiary care institution. CMAJ. 2004;170:793-8.

6. Maunder RG, Lancee WJ, Rourke S, Hunter JJ, Goldbloom D, Balderson K, et al. Factors associated with the psychological impact of severe acute respiratory syndrome on nurses and other hospital workers in Toronto. Psychosom Med. 2004;66:938-42.

7. Bai Y, Lin CC, Lin CY, Chen JY, Chue CM, Chou P. Survey of stress reactions among health care workers involved with the SARS outbreak. Psychiatr Serv. 2004;55:1055-7.

8. Ho SM, Kwong-Lo RS, Mak CW, Wong JS. Fear of severe acute respiratory syndrome (SARS) among health care workers. J Consult Clin Psychol. 2005;73:344-9.

9. Wong TW, Yau JK, Chan CL, Kwong RS, Ho SM, Lau CC, et al. The psychological impact of severe acute respiratory syndrome outbreak on healthcare workers in emergency departments and how they cope. Eur J Emerg Med. 2005;12:13-8.

10. Maunder R, Lancee WJ, Rourke SB, Hunter J, Goldbloom DS, Petryshen PM, et al. The experience of the 2003 SARS outbreak as a traumatic stress among frontline healthcare workers in Toronto: lessons learned. In: McLean AR, May RM, Pattison J, Weiss RA, editors. SARS: a case study in emerging infections. Oxford: Oxford University Press, 2005. p. 96-106. 
11. Verma S, Mythily S, Chan YH, Deslypere JP, Teo EK, Chong SA. Post-SARS psychological morbidity and stigma among general practitioners and traditional Chinese medicine practitioners in Singapore. Ann Acad Med Singapore. 2004;33:743-8.

12. Chen CS, Wu HY, Yang P, Yen CF. Psychological distress of nurses in Taiwan who worked during the outbreak of SARS. Psychiatr Serv. 2005;56:76-9.

13. Yehuda R. Risk and resilience in posttraumatic stress disorder. J Clin Psychiatry. 2004;65(Suppl 1):29-36.

14. Drosten C, Gunther S, Preiser W, van der Werf S, Brodt HR, Becker $\mathrm{S}$, et al. Identification of a novel coronavirus in patients with severe acute respiratory syndrome. N Engl J Med. 2003;348:1967-76.

15. Rota PA, Oberste MS, Monroe SS, Nix WA, Campagnoli R, Icenogle JP, et al. Characterization of a novel coronavirus associated with severe acute respiratory syndrome. Science. 2003;300:1394-9.

16. Kuiken T, Fouchier RA, Schutten M, Rimmelzwaan GF, van Amerongen G, van Riel D, et al. Newly discovered coronavirus as the primary cause of severe acute respiratory syndrome. Lancet. 2003;362:263-70.

17. Peiris JS, Lai ST, Poon LL, Guan Y, Yam LY, Lim W, et al. Coronavirus as a possible cause of severe acute respiratory syndrome. Lancet. 2003;361:1319-25.

18. Slovic P. Perception of risk. Science. 1987;236:280-5.

19. Eisenman DP, Stein BD, Tanielian TL, Pincus HA. Terrorism's psychologic effects and their implications for primary care policy, research, and education. J Gen Intern Med. 2005;20:772-6.

20. Horowitz M, Wilner NJ, Alvarez W. Impact of Events Scale: a measure of subjective stress. Psychosom Med. 1979;41:209-18.

21. Horowitz MJ. Stress response syndromes: a review of posttraumatic and adjustment disorders. Hosp Community Psychiatry. 1986;37:241-9.

22. Kessler RC, Andrews G, Colpe LJ, Hiripi E, Mroczek DK, Normand SL, et al. Short screening scales to monitor population prevalences and trends in non-specific psychological distress. Psychol Med. 2002;32:959-76.

23. Maslach C, Jackson SE. Burnout in health professions: a psychological analysis. In: Snader GS, Suls J, editors. Social psychology of health and illness. Hillsdale (NJ): Erlbaum; 1982. p. 227-51.

24. Maslach C, Jackson SE. Maslach Burnout Inventory. Palo Alto (CA): Consulting Psychologists Press; 1986.

25. Maslach C, Jackson SE, Leitner MP. Maslach Burnout Inventory. 3rd ed. Third edition. In: Zalaquett CP, Woods RJ, editors. Evaluating stress: a book of resources. Lanham (MD): Scarecrow Press; 1997. p. 191-218.
26. Koh D, Lim MK, Chia SE, Ko SM, Qian F, Ng V, et al. Risk perception and impact of severe acute respiratory syndrome (SARS) on work and personal lives of healthcare workers in Singapore: What can we learn? Med Care. 2005;43:676-82.

27. Folkman S, Lazarus RS. Ways of coping questionnaire manual. Palo Alto (CA): Mind Garden; 1988.

28. Fraley RC, Waller NG, Brennan KA. An item response theory analysis of self-report measures of adult attachment. J Pers Soc Psychol. 2000;78:350-65.

29. Tseng HC, Chen TF, Chou SM. SARS: Key factors in crisis management. J Nurs Res. 2005;13:58-65.

30. Leszcz M. Group psychological perspectives on staff coping with SARS. New York: American Psychiatric Association Annual Meeting, May 6, 2004.

31. Kerr MS, Laschinger HKS, Severin CN, Almost JM, Shamian J. New strategies for monitoring the health of Canadian nurses: results of collaborations with key stakeholders. Can J Nurs Leadersh. 2005;18:67-81.

32. Aiken LH, Clarke SP, Sloane DM, Sochalski J, Silber JH. Hospital nurse staffing and patient mortality, nurse burnout, and job satisfaction. JAMA. 2002;288:1987-93.

33. Aiken LH, Clarke S, Sloane DM. Hospital staffing, organization, and quality of care: cross-national findings. Int J Qual Health Care. 2002;14:5-13.

34. Laschinger HKS, Finegan J, Shamian J, Wilk P. Impact of structural and psychological empowerment on job strain in nursing work settings: expanding Kanter's model. J Nurs Adm. 2001;31:260-72.

35. Guhde J. When orientation ends: supporting the new nurse who is struggling to succeed. J Nurses Staff Dev. 2005;21:145-9.

36. Yank GR, Barber JW, Hargrove DS, Whitt PD. The mental health treatment team as a work group: team dynamics and the role of the leader. Psychiatry. 1992;55:250-64.

37. Bowlby J. Attachment and loss: Vol 1: attachment. New York: Basic Books; 1969.

38. Mikulincer M, Florian V, Weller A. Attachment styles, coping strategies, and posttraumatic psychological distress: the impact of the Gulf War in Israel. J Pers Soc Psychol. 1993;64:817-26.

39. Maunder RG, Lancee WJ, Nolan RP, Hunter JJ, Tannenbaum DW. The relationship of attachment insecurity to subjective stress and autonomic function during standardized acute stress in healthy adults. J Psychosom Res. 2006;60:283-90.

Address for correspondence: Robert G. Maunder, Department of Psychiatry, Mount Sinai Hospital, 600 University Ave, Toronto, Ontario M5G 1X5; email: rmaunder@mtsinai.on.ca

\section{emerging infectious diseases $\mathrm{O} M \mathrm{li} \mathrm{i} \mathrm{e}$}

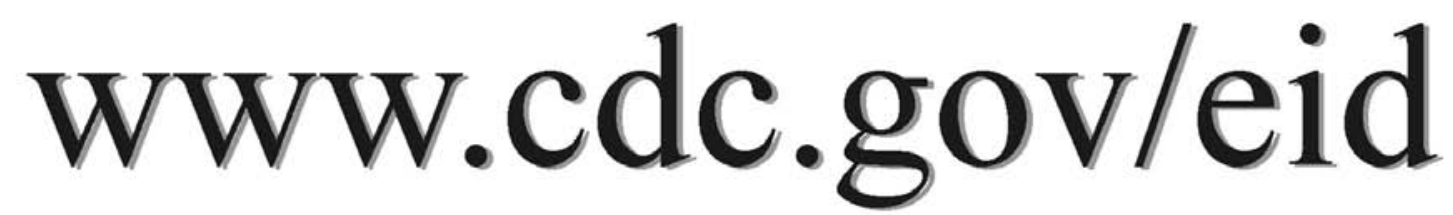

To receive tables of contents of new issues send an email to listserve@cdc.gov with subscribe eid-toc in the body of your message. 